\title{
Toward a Comprehensive Model of Foreign Language Vocabulary Learning: To Integrate Instructed Learning with Incidental Learning
}

\author{
Yanmei Liu ${ }^{1}$ \\ ${ }^{1}$ School of Applied English Studies, Shandong University of Finance and Economics, Jinan, China \\ Correspondence: Yanmei Liu (19790304), School of Applied English Studies, Shandong University of Finance \\ and Economics, Jinan 250014, China. E-mail: lym7935@hotmail.com
}

Received: April 7, 2013 Accepted: May 30, 2013 Online Published: August 1, 2013

doi:10.5539/ass.v9n10p142 URL: http://dx.doi.org/10.5539/ass.v9n10p142

\begin{abstract}
The integration of vocabulary instruction and incidental learning has been proposed by many scholars, but the effective way to integrate these two approaches in vocabulary acquisition is still unclear. In order to know the roles these two approaches play in lexical learning, an empirical study was carried out. Three groups were randomly assigned to three treatments: incidental vocabulary acquisition through one reading, vocabulary instruction, and vocabulary instruction plus one reading. Both the immediate acquisition and delayed retention of the target words (including part of speech, semantic meaning, collocation and production) were examined and compared among the three groups. The study revealed that intentional instruction is significantly better than incidental learning in all four aspects of vocabulary leaning, but reading after instruction can consolidate and deepen learners' leaning of words that have been taught. A comprehensive model was suggested to integrate instructed learning and incidental learning in foreign language vocabulary acquisition.
\end{abstract}

Keywords: vocabulary instruction, incidental vocabulary acquisition, a comprehensive model

\section{Introduction}

\subsection{Background of the Study}

Words, as the building blocks of language, play an enormously important role for foreign language learners. How words can be best learned has been brought to the focus of attention of many practitioners as well as many researchers. In vocabulary acquisition, a distinction is frequently made between incidental and intentional vocabulary acquisition, also called indirect and direct vocabulary leaning respectively. Intentional learning involves the deliberate commitment to memory of words, with the main purpose to acquire vocabulary knowledge; while incidental learning involves the "picking up" of words by engaging in a variety of communicative activities, during which the learner's attention is focused on the meaning rather than the form of language (Hulstijn, 2003). Vocabulary learning in this approach thus is a "byproduct" (Huckin \& Coady, 1999) of any activity not explicitly geared to vocabulary learning. The most frequently quoted example is vocabulary learning as a by-product of reading.

Which way is better in promoting learner's vocabulary knowledge? Many argue that most, if not all, second language vocabulary should be incidentally acquired through extensive reading like L1 vocabulary (Krashen, 1989; Zahar et al., 2001). A lot of research has been conducted on the effect of extensive reading on incidental vocabulary learning. Among these researches, some confirm the effectiveness of learning through extensive reading (Pellicer-Sánchez \& Schmitt, 2010; Kweon \& Kim, 2008), but most of them (Waring \& Takaki, 2003; Horst et al., 1998; Lahav, 1996; Knight, 1994) show that learners incidentally gain small amounts of vocabulary knowledge from each meaning focused reading. So intentional learning is proposed as the main way to improve vocabulary knowledge (Wang, 2010; Xun, 2006).

Nowadays with more and deeper study on the second language vocabulary acquisition, the traditional dichotomy of incidental and intentional vocabulary learning was challenged and more and more scholars prefer to accept that incidental and intentional learning are not contradictory, and both forms of learning can be complementary to each other and "can be usefully integrated"(Schmitt, 2008) in vocabulary acquisition.

Numerous empirical studies have been carried out to explore the effectiveness of the combination of intentional and incidental learning in vocabulary acquisition (Dong, 2001; Lee \& Muncie, 2006; Min, 2008; Wu et al., 
2010), but which aspects of vocabulary learning will be best facilitated by these two different approaches and how we can integrate these two approaches in vocabulary learning are still open to discussion. Furthermore, almost all studies examined the effect of incidental learning through reading on acquisition of unknown words, seemingly neglecting the effect of reading on acquisition of words with partial knowledge.

\subsection{Research Questions}

Intentional learning includes many forms, of which intentional instruction is a most important way for foreign language learners. What is the role of intentional instruction in vocabulary acquisition? What is the effect of incidental vocabulary learning through reading? Will reading facilitate the learning of unknown words as well as words that have been taught? And how should we integrate intentional and incidental learning in vocabulary acquisition? To explore a comprehensive model of foreign language vocabulary learning, an empirical study with three parallel groups will be designed to test the effect of three different treatments: incidental vocabulary acquisition through one reading, vocabulary instruction, and vocabulary instruction plus one reading.

Knowledge of words, as is wildly acknowledged, is multidimensional (Nation, 1990). In order to capture as many features as possible, four aspects will be contained to test learners' vocabulary acquisition: part of speech, semantic meaning, collocation and colligation, and the production of words with the cue of context.

Research questions:

1) How do different learning approaches (vocabulary instruction, incidental vocabulary learning and vocabulary instruction plus one reading) affect learners' acquisition of words (part of speech, semantic meaning, collocation and colligation, and the production of words with the cue of context)?

2) How do different learning approaches (vocabulary instruction, incidental vocabulary learning and vocabulary instruction plus one reading) affect learners' retention of words (part of speech, semantic meaning, collocation and colligation, and the production of words with the cue of context)?

\section{Research Design}

\subsection{Subjects}

Ninety-two freshmen of 3 parallel classes of Shandong University of Finance and Economics participated in this experiment. Two students dropped out in the delayed test, so altogether 90 students serve as subjects. SPSS 19.0 was used to examine the English achievement in college entrance examination and found there was no significant difference among these three groups, indicating participants of the three groups are of the same proficiency level before test.

\subsection{Reading Material}

When preparing the reading passage, we saw to it that the text was of an appropriate difficulty level with a lexical density that would allow general comprehension and that it was interesting enough to encourage the subjects to engage in the reading. Eventually a short essay of 605 words entitled "A merchant and his four wives" was selected. To ensure the passage is in an appropriate difficulty level, a pretest was conducted in which 20 students of a similar English proficiency level who did not participate in the study were asked to underline the words in the passage whose meaning they did not know. Twelve to twenty unknown words were underlined, indicating $96.7-98.1 \%$ of words are familiar to all subjects. The lexical density of this passage thus is in accordance with Laufer's (1992) criterion that a minimum of $95 \%$ of the words in a text need to be known for any reasonable chance of effective guessing.

\subsection{Target Words}

Of the 12 words unknown to all participants, 8 were chosen as the target words according to the richness of the context, of which 4 were verbs, 3 were nouns and 1 was adjective. Four words were chosen as distracters. Altogether 12 words will be examined.

\subsection{Instruments}

In order to capture as many aspects of learners' acquisition of vocabulary as possible, four aspects of test will be included, part of speech, semantic meaning, collocation and colligation, and production of words with the cue of context. Each aspect will be tested separately to avoid any hints from other aspects. In part of speech and semantic meaning part, English words will be given, and subjects are required to write down the Chinese meaning and determine their part of speech; in collocation and colligation part, subjects are asked to match the target words in column A with the words or phrases in column B to form collocation or colligation according to 
the reading material; in the part of production of target words, subjects are required to complete the words with the aid of context and the initial one or few letters( Laufer \& Nation, 1999).

\subsection{Procedures}

The study was conducted in four stages.

\subsubsection{Pilot Study}

The purpose to have the pilot study is two-folded: one is to exclude the words that students might already know and to ensure that the material would be at an appropriate level of difficulty suitable for comprehension; the other is to make sure the proper order to hand out different parts of test. Twenty students of a similar English proficiency level who did not participate in the study were asked to underline the unknown words and read the passage and finish different parts of vocabulary test. According to the pilot study, the production of target words should be handed out first to avoid test effect.

\subsubsection{Treatment}

Three groups will be randomly assigned to receive different treatment:

Treatment 1: Reading only (Group 1)

Group 1 would be asked to read the passage in 8 minutes without notifying them there would be vocabulary test after reading.

Treatment 2: Vocabulary Instruction only (Group 2)

Group 2 will be taught the 12 words (8 target words and 4 distracters) explicitly in about 12 minutes, including the part of speech, semantic meaning, a sentence to explain its usage and derivational words related, if any.

Treatment 3: Instruction +Reading (Group 3)

For group 3, first the 12 words will be taught in 12 minutes and then the reading material will be assigned to finish in 8 minutes. The subjects will not be told in advance there will be vocabulary test after reading.

\subsubsection{Immediate test}

Upon the completion of each treatment, each group will be asked to finish a vocabulary test of three parts separately: firstly the production of target words part was handed out, which was followed by the part of speech and semantic meaning part and the collocation and colligation part. For each part, subjects were asked to finish and hand it in in 3 minutes.

\subsubsection{Delayed Test}

Two weeks later, the three groups will directly receive the same test again.

\subsection{Scoring}

Two teachers marked the test paper according to the same criterion and only the data of the 8 target words were collected. In production part, one score will be given if the correct form is spelt, 0.5 will be assigned if part of the word is spelt correctly (for example, pursuit is spelt as persuit), the wrong spelling will receive zero. In part of speech part, semantic meaning part, and the collocation and colligation part, one score will be assigned if the right answer is given, and zero will be assigned for a wrong answer. The interrater reliability is $98 \%$. The scores of immediate and delayed tests were then submitted to the One-way ANOVA respectively.

\section{Results and Data Analysis}

Oneway ANOVA was adopted to analyze the results from immediate test and the delayed test. Tukey's LSD was used to have the post hoc multiple comparisons.

\subsection{Results of Immediate Test}

Table 1. Descriptive results of the immediate vocabulary test

\begin{tabular}{cccccc}
\hline & group & $\mathrm{N}$ & mean & SD & Std. Error \\
\hline production & 1.00 & 29 & .8448 & .80293 & .14910 \\
& 2.00 & 30 & 3.1167 & 1.00587 & .18365 \\
& 3.00 & 32 & 4.0469 & 1.22711 & .21692 \\
& Total & 91 & 2.7198 & 1.69018 & .17718
\end{tabular}




$\begin{array}{cccccc}\text { Part of speech } & 1.00 & 29 & 4.1724 & 1.62720 & .30216 \\ & 2.00 & 30 & 5.5667 & 1.19434 & .21805 \\ & 3.00 & 32 & 5.2188 & 1.64090 & .29007 \\ \text { Semantic } & \text { Total } & 91 & 5.0000 & 1.59861 & .16758 \\ \text { meaning } & 1.00 & 29 & 1.2759 & 1.33354 & .24763 \\ & 2.00 & 30 & 4.7333 & 2.01603 & .36807 \\ & 3.00 & 32 & 4.4688 & 1.56544 & .27673 \\ \text { collocation } & \text { Total } & 91 & 3.5385 & 2.26719 & .23767 \\ & 1.00 & 29 & 2.8276 & 1.75395 & .32570 \\ & 2.00 & 30 & 3.9667 & 1.44993 & .26472 \\ & 3.00 & 32 & 5.4063 & 1.84669 & .32645 \\ & \text { Total } & 91 & 4.1099 & 1.98579 & .20817\end{array}$

Descriptive data from table 1 revealed group 1 did acquire some vocabulary knowledge merely through reading, but the acquisition rate was much lower than group2 and group 3 in all four aspects of vocabulary knowledge, and production of target words with the help of context was done worst of the four aspects. Statistics also revealed that group 3 outperformed group 2 in collocation and production test of the target words.

Table 2. Oneway ANOVA of the immediate vocabulary test

\begin{tabular}{ccccccc}
\hline & & Sum of Squares & df & Mean Square & F & Sig. \\
\hline production & Between Groups & 163.031 & 2 & 81.516 & 76.253 & .000 \\
& Within Groups & 94.073 & 88 & 1.069 & & \\
& Total & 257.104 & 90 & & & \\
Part of & Between Groups & 31.027 & 2 & 15.513 & 6.861 & .002 \\
speech & Within Groups & 198.973 & 88 & 2.261 & & \\
& Total & 230.000 & 90 & & & \\
Semantic & Between Groups & 218.987 & 2 & 109.493 & 39.550 & .000 \\
meaning & Within Groups & 243.629 & 88 & 2.769 & & \\
& Total & 462.615 & 90 & & & \\
collocation & Between Groups & 102.078 & 2 & 51.039 & 17.765 & .000 \\
& Within Groups & 252.823 & 88 & 2.873 & & \\
& Total & 354.901 & 90 & & & \\
\hline
\end{tabular}

Table 2 reveals that the mean scores of the three groups differ significantly from each other in all four aspects of vocabulary acquisition $(\mathrm{F}=76.253, \mathrm{p}=.000 ; \mathrm{F}=6.861, \mathrm{p}=.002 ; \mathrm{F}=39.550, \mathrm{p}=.000 ; \mathrm{F}=17.765, \mathrm{p}=.000$ respectively).

Table 3. Tukey's LSD based on the immediate vocabulary test

\begin{tabular}{cccccc}
\hline Dependent Variable & (I) group & (J) group & Mean Difference (I-J) & Std. Error & Sig. \\
\hline production & 1.00 & 2.00 & $-2.27184^{*}$ & .26925 & .000 \\
& & 3.00 & $-3.20205^{*}$ & .26508 & .000 \\
\multirow{2}{*}{2.00} & 1.00 & $2.27184^{*}$ & .26925 & .000 \\
& 3.00 & $-.93021^{*}$ & .26276 & .001 \\
& \multirow{2}{*}{3.00} & 1.00 & $3.20205^{*}$ & .26508 & .000 \\
& & 2.00 & $.93021^{*}$ & .26276 & .001
\end{tabular}




\begin{tabular}{|c|c|c|c|c|c|}
\hline \multirow[t]{6}{*}{ Part of speech } & 1.00 & 2.00 & $-1.39425^{*}$ & .39158 & .001 \\
\hline & & 3.00 & $-1.04634 *$ & .38552 & .008 \\
\hline & 2.00 & 1.00 & $1.39425^{*}$ & .39158 & .001 \\
\hline & & 3.00 & .34792 & .38213 & .365 \\
\hline & 3.00 & 1.00 & $1.04634^{*}$ & .38552 & .008 \\
\hline & & 2.00 & -.34792 & .38213 & .365 \\
\hline \multirow{6}{*}{ Semantic meaning } & 1.00 & 2.00 & $-3.45747^{*}$ & .43330 & .000 \\
\hline & & 3.00 & $-3.19289 *$ & .42659 & .000 \\
\hline & 2.00 & 1.00 & $3.45747^{*}$ & .43330 & .000 \\
\hline & & 3.00 & .26458 & .42285 & .533 \\
\hline & 3.00 & 1.00 & $3.19289^{*}$ & .42659 & .000 \\
\hline & & 2.00 & -.26458 & .42285 & .533 \\
\hline \multirow[t]{6}{*}{ collocation } & 1.00 & 2.00 & $-1.13908^{*}$ & .44140 & .012 \\
\hline & & 3.00 & $-2.57866^{*}$ & .43457 & .000 \\
\hline & 2.00 & 1.00 & $1.13908^{*}$ & .44140 & .012 \\
\hline & & 3.00 & $-1.43958^{*}$ & .43075 & .001 \\
\hline & 3.00 & 1.00 & $2.57866^{*}$ & .43457 & .000 \\
\hline & & 2.00 & $1.43958 *$ & .43075 & .001 \\
\hline
\end{tabular}

*The mean difference is significant at the .05 level.

Detailed view of multiple comparisons was provided by table 3. Statistics show that group 1 was significantly lower than group 2 and group 3 in all four aspects of vocabulary acquisition and group 3 performed significantly better than group 2 in production and collocation of the target words.

3.2 Results of Delayed Test

Table 4. Descriptive results of the delayed vocabulary test

\begin{tabular}{cccccc}
\hline & group & $\mathrm{N}$ & Mean & SD & Std. Error \\
\hline production & 1.00 & 29 & .8448 & .90735 & .34409 \\
& 2.00 & 30 & 2.4167 & 2.26321 & .37041 \\
& 3.00 & 32 & 3.3125 & 2.54555 & .32630 \\
& Total & 91 & 2.2308 & 2.27707 & .20898 \\
Part of speech & 1.00 & 29 & 3.8276 & 1.85297 & .24951 \\
& 2.00 & 30 & 5.2333 & 2.02882 & .42729 \\
& 3.00 & 32 & 5.1406 & 1.84581 & .39296 \\
Semantic meaning & Total & 91 & 4.7527 & 1.99356 & .27041 \\
& 1.00 & 29 & 1.3448 & 1.34366 & .36306 \\
& 2.00 & 30 & 4.6167 & 2.34036 & .40139 \\
collocation & 3.00 & 32 & 4.9531 & 2.22290 & .32179 \\
& Total & 91 & 3.6923 & 2.57959 & .23741 \\
& 1.00 & 29 & 2.4138 & 1.95516 & .16849 \\
& 2.00 & 30 & 4.1667 & 2.19848 & .41320 \\
& 3.00 & 32 & 5.0938 & 1.82030 & .44999 \\
& Total & 91 & 3.9341 & 2.26472 & .23870 \\
\hline
\end{tabular}


Descriptive results reveal the difference between group 1 and group 2 and the difference between group 1 and group 3 maintained, although the difference between group 2 and group 3 became blurred.

Table 5. Oneway ANOVA of the delayed vocabulary test

\begin{tabular}{|c|c|c|c|c|c|c|}
\hline & & Sum of Squares & $\mathrm{df}$ & Mean Square & $\mathrm{F}$ & Sig. \\
\hline \multirow[t]{3}{*}{ production } & Between Groups & 94.185 & 2 & 47.093 & 11.126 & .000 \\
\hline & Within Groups & 372.468 & 88 & 4.233 & & \\
\hline & Total & 466.654 & 90 & & & \\
\hline \multirow{3}{*}{ Part of speech } & Between Groups & 36.565 & 2 & 18.283 & 5.010 & .009 \\
\hline & Within Groups & 321.122 & 88 & 3.649 & & \\
\hline & Total & 357.687 & 90 & & & \\
\hline \multirow[t]{3}{*}{ Semantic meaning } & Between Groups & 236.312 & 2 & 118.156 & 28.678 & .000 \\
\hline & Within Groups & 362.573 & 88 & 4.120 & & \\
\hline & Total & 598.885 & 90 & & & \\
\hline \multirow[t]{3}{*}{ collocation } & Between Groups & 111.684 & 2 & 55.842 & 14.044 & .000 \\
\hline & Within Groups & 349.920 & 88 & 3.976 & & \\
\hline & Total & 461.604 & 90 & & & \\
\hline
\end{tabular}

Oneway ANOVA analysis shows that significant difference among these three groups in all four aspects of vocabulary learning still exists with all p levels below .05 .

Table 6. Tukey's LSD based on the delayed vocabulary test

\begin{tabular}{|c|c|c|c|c|c|}
\hline dependent variable & (I)group & (J) group & Mean difference (I-J) & Std. Error & Sig. \\
\hline \multirow[t]{6}{*}{ production } & 1.00 & 2.00 & $-1.57184^{*}$ & .53576 & .004 \\
\hline & & 3.00 & $-2.46767^{*}$ & .52747 & .000 \\
\hline & 2.00 & 1.00 & $1.57184^{*}$ & .53576 & .004 \\
\hline & & 3.00 & -.89583 & .52283 & .090 \\
\hline & 3.00 & 1.00 & $2.46767 *$ & .52747 & .000 \\
\hline & & 2.00 & .89583 & .52283 & .090 \\
\hline \multirow[t]{6}{*}{ part of speech } & 1.00 & 2.00 & $-1.40575^{*}$ & .49746 & .006 \\
\hline & & 3.00 & $-1.31304 *$ & .48976 & .009 \\
\hline & 2.00 & 1.00 & $1.40575^{*}$ & .49746 & .006 \\
\hline & & 3.00 & .09271 & .48546 & .849 \\
\hline & 3.00 & 1.00 & $1.31304 *$ & .48976 & .009 \\
\hline & & 2.00 & -.09271 & .48546 & .849 \\
\hline \multirow[t]{6}{*}{ Semantic meaning } & 1.00 & 2.00 & $-3.27184^{*}$ & .52859 & .000 \\
\hline & & 3.00 & $-3.60830^{*}$ & .52041 & .000 \\
\hline & 2.00 & 1.00 & $3.27184^{*}$ & .52859 & .000 \\
\hline & & 3.00 & -.33646 & .51584 & .516 \\
\hline & 3.00 & 1.00 & $3.60830^{*}$ & .52041 & .000 \\
\hline & & 2.00 & .33646 & .51584 & .516 \\
\hline \multirow[t]{6}{*}{ collocation } & 1.00 & 2.00 & $-1.75287^{*}$ & .51929 & .001 \\
\hline & & 3.00 & $-2.67996^{*}$ & .51125 & .000 \\
\hline & 2.00 & 1.00 & $1.75287^{*}$ & .51929 & .001 \\
\hline & & 3.00 & -.92708 & .50676 & .071 \\
\hline & 3.00 & 1.00 & $2.67996^{*}$ & .51125 & .000 \\
\hline & & 2.00 & .92708 & .50676 & .071 \\
\hline
\end{tabular}

* The mean difference is significant at the .05 level. 
Post hoc comparisons clearly reveal significant difference exists both between group 1 and group 2 and between group 1 and group 3 in all four aspects of vocabulary learning, but there is no significant difference between group 2 and group 3 in all four aspects of vocabulary acquisition, namely the advantage in collocation and production of target words that group 3 had displayed during immediate test suffered severe attrition after two weeks' delay.

\section{Discussion}

1) Incidental vocabulary learning through reading does occur in the acquisition of words' part of speech, semantic meaning, collocation and production of target words, although the last aspect was worst learned among the four aspects(part of speech $>$ collocation $>$ semantic meaning $>$ production).

Krashen (1985) suggests the most effective way for learners to develop language proficiency is to provide them with comprehensible input, that is $\mathrm{i}+1$ (i stands for learners' current level) level of reading or listening material. Although it is hard to determine whether the $95 \%$ lexical density equals the $i+1$ level, it seems that learners could guess out some word knowledge with background knowledge that learners themselves bring and the rich context provided in the reading passage.

Statistics show that words' part of speech was best learned through reading with 4.17(52\%) in the immediate test and 3.83(48\%) in the delayed test, which is much higher than the $20 \%$ in Pellicer-Sánchez \& Schmitt's study (2010). It is not surprising that readers employ their grammatical knowledge when reading words in syntax and determine the word class, which may be hard to decide in isolation. Incidental acquisition of words' collocation and colligation goes second, as incidental acquirer increases his or her chances to get a feel for collocations and colligations (Bahns \& Eldaw, 1993) through the contextualized input and a richer sense of a word will be learned. The incidental acquisition of word meaning is not as promising as many studies have revealed (Kweon \& Kim, 2008; Pellicer-Sánchez \& Schmitt, 2010) perhaps it is due to the limited length of the reading passage and the infrequent exposure to the target words in this study. However, production of target words turned out to be problematic through incidental learning with only $0.8448(10 \%)$ in both tests. This may be caused by the nature of reading, during which readers read for meaning and more attention is assigned to the coherence of the passage, leaving form neglected.

2) Intentional vocabulary instruction turned out to be better than incidental vocabulary learning in all four aspects of vocabulary acquisition. Results from this study reveal that meaningful learning of vocabulary knowledge can accrue from reading, but that the amount of incidental learning is unlikely to match the amount available from an explicit teaching approach. Pos hoc multiple comparisons on both the immediate and delayed test show there is significant difference between group 1 (incidental learning) and group 2(vocabulary instruction) in all four aspects of vocabulary learning, which is in compliance with the result of a number of studies reviewed by Laufer (2005).

The different effect of vocabulary instruction and incidental learning can be explained by the different attention type that learners bring to lexical learning. In vocabulary instruction, word learning is the main task and learners' attention is focused on various aspects of lexical knowledge, thus absorbing more information about words. In incidental learning, however, word learning is subordinate to establishing coherence of the whole text, and thus is a subtask for learners. Accordingly, more attention is given to the text coherence and less attention assigned to lexical learning.

From a psychological view, elaboration on features of new words promotes their retention. This means that the more attention that is paid to the formal and semantic aspects of words and the richer the associates that are made with existing knowledge (e.g., in the form of establishing similarities and contrasts between old and new knowledge), the higher are the chances that the new information will be retained (in Laufer \& Hulstijn, 2001). As is mentioned in the treatment, learners were provided various aspects of lexical knowledge (the part of speech, semantic meaning, a sentence to explain its usage and derivational words related, if any) in vocabulary instruction, which is conducive for learners to process the words from various aspects and establish association with the knowledge in long-term memory and thus achieve better acquisition and retention of lexical knowledge.

3) Immediate reading after vocabulary instruction seems to better facilitate learners' contextual knowledge of instructed words. By comparing the immediate test of group 2 (vocabulary instruction only) and group 3 (vocabulary instruction plus reading), it is found that group 3 significantly outperformed group 2 in collocation and colligation part and production of target words with the help of context. That is, immediate reading after instruction enhances learners' acquisition of contextual knowledge of the target words.

As Schmitt (2008) has mentioned, intentional learning is best for learners to establish the meaning-form link and 
once this initial meaning-form link is established, it is crucial to consolidate it with repeated exposures. With the meaning-form mapping in mind, learners need not take much effort to guess the meaning of the word and thus save much attention and cognitive resources to process the deep knowledge of the word.

From a psychological view, timely contact with the target words after instruction can deepen the trace of learners' memory of target words and keep them from forgetting. Repeated exposure to the target words will also add the retrieval frequency of the target words and increase learners' processing of the target words, thus strengthening memory of the word.

4) Only one reading is far from enough to consolidate words' knowledge, so extensive reading and constant exposure to the target words should be greatly encouraged to fully acquire a word. Statistics in delayed test also show that the advantage in contextual knowledge that group 3 displayed in immediate test was significantly undermined and was reduced to the same level as group 2 after two weeks' delay. That means only one reading after instruction is far from enough to consolidate the contextual learning of lexis. If too much time has passed between the previous meeting and the present encounter with the word, then the present encounter is effectively not a repetition but is like a first encounter. Vocabulary learning is incremental in nature and lexical items need to be met many times in order to be learned (Nation, 2001). Enough number of exposures is necessary to promote incidental learning through reading. Through timely and repeated exposures, readers will not only strengthen the path link between meaning and form, and gradually recognize an item automatically, but also can enhance the knowledge of a word by developing other types of lexical knowledge.

\section{Limitations of the Study}

Inevitably, there are numerous limitations to note in this study. The nature and length of the reading material did not allow us to test as many targets words and word knowledge aspects as we would have liked. Also, due to the short length of the reading material, same frequency of target words was not guaranteed and frequency of encounter on vocabulary acquisition was not examined.

The nature of the design only allowed us to compare the means of three different groups, and individual differences such as motivation, interest, background knowledge etc. could not be taken into account in the explanation of the test results.

\section{Conclusion}

As is revealed by this study, both vocabulary instruction and incidental vocabulary learning have their merits and demerits. Vocabulary instruction is effective in promoting learners' learning of all aspects of word knowledge, especially in forming the initial meaning-form link, but the number of words that will be covered in instruction is limited, and it is impossible to contain all contextual knowledge of words in teaching. Additionally, teaching vocabulary in isolation is much more tedious both for learners and teachers. Incidental learning, on the other hand, can compensate vocabulary instruction by engaging learners in reading and at the same time by enabling learners to learn new words and consolidate words with partial knowledge. But incidental learning is less effective in enhancing learners' productive ability of target words, so intentional learning should be employed to push the receptive words to productive level.

Therefore, it is no wise to exaggerate either one of the incidental learning and vocabulary instruction, and each of them has their own role to play in facilitating vocabulary learning and should complement each other and be integrated properly in the process of vocabulary acquisition.

\section{References}

Bahns, J., \& Eldaw, M. (1993). Should we teach EFL students collocations? System, 21, 101-114. http://dx.doi.org/10.1016/0346-251X(93)90010-E

Dong, Y. P. (2001). Direct and indirect L2 vocabulary learning in the communicative approach. Foreign Language Teaching and Research, 3, 186-192.

Horst, M., Cobb, T., \& Meara, P. (1998). Beyond a clockwork orange: Acquiring second language vocabulary through reading. Reading in a Foreign Language, 11, 207-223.

Huckin, T., \& Coady, J. (1999). Incidental vocabulary acquisition in a second language: A review. Studies in Second Language Acquisition, 21(2), 181-193. http://dx.doi.org/10.1017/S0272263199002028

Hulstijn, J. (2003). Incidental and intentional learning. In C. J. Doughty, \& M. H. Long (Eds.), The Handbook of Second Language Acquisition. Blckwell Publishing Ltd. http://dx.doi.org/10.1002/9780470756492.ch12

Knight, S. M. (1994). Dictionary use while reading: The effects on comprehension and vocabulary acquisition 
for students of different verbal abilities. Modern Language Journal, 78, 285-299. http://dx.doi.org/10.1111/j.1540-4781.1994.tb02043.x

Krashen, S. (1985). The input hypothesis: Issues and implications. London, U.K.

Krashen, S. (1989). We acquire vocabulary and spelling by reading: Additional evidence for the Input $\begin{array}{lllll}\text { Hypothesis. The Modern } & \text { Language Journal, }\end{array}$ http://dx.doi.org/10.1111/j.1540-4781.1989.tb05325.x

Kweon, S., \& Kim, H. (2008). Beyond raw frequency: Incidental vocabulary acquisition in extensive reading. Reading in a Foreign Language, 2, 191-215.

Lahav, J. (1996).Vocabulary Acquisition through Extensive Reading: "Incidental" and Controlled Acquisition Compared. Unpublished Master's thesis, University of Haifa.

Laufer, B. (1992). How much lexis is necessary for reading comprehension? In H. Bejoint, \& P. Arnaud (Eds.), Vocabulary and Applied Linguistics (pp. 126-132). Macmillan.

Laufer, B. (2005). Focus on form in second language vocabulary learning. EUROSLA Yearbook, 5, 223-250. http://dx.doi.org/10.1075/eurosla.5.11lau

Laufer, B., \& Hulstijn, J. (2001) incidental vocabulary acquisition in a second language: the construct of task-induced involvement. Applied linguistics, 22(1), 1-26. http://dx.doi.org/10.1093/applin/22.1.1

Laufer, B., \& Nation, P. (1999) A Vocabulary Size Test of Controlled Productive Ability. Language Testing, 16, 36-45. http://dx.doi.org/10.1191/026553299672614616

Lee, S. H., \& Muncie, J. (2006). From Receptive to Productive: Improving ESL Learners' Use of Vocabulary in a Postreading Composition Task. TESOL Quarterly, 2, 295-320. http://dx.doi.org/10.2307/40264524

Min, H. T. (2008). EFL vocabulary acquisition and retention: Reading plus vocabulary enhancement activities $\begin{array}{lllll}\text { and narrow } \quad \text { Leading. } & \text { Language }\end{array}$ http://dx.doi.org/10.1111/j.1467-9922.2007.00435.x

Nation, I. S. P. (1990). Teaching and Learning Vocabulary. New York. Newburry house Publishers.

Nation, I. S. P. (2001). Learning vocabulary in another language. Cambridge: Cambridge University Press. http://dx.doi.org/10.1017/CBO9781139524759

Pellicer-Sánchez, A., \& Schmitt, N. (2010). Incidental vocabulary acquisition from an authentic novel: Do Things Fall Apart? Reading in a Foreign Language, 1, 31-55.

Schmitt, N. (2008). Instructed second language vocabulary learning. Language Teaching Research, 12, 329-363. http://dx.doi.org/10.1177/1362168808089921

Wang, Z. X. (2010). An Information Processing Model-based Research of Incidental Vocabulary Learning. Foreign Language Research, 1, 108-112.

Waring, R., \& Takaki, M. (2003). At what rate do learners learn and retain new vocabulary from reading a graded reader? Reading in a Foreign Language, 15, 130-163.

Wu, J. S., Lang, J. G., \& Fu, L. (2010). L2 vocabulary acquisition study based on "Reading Plus". Modern Foreign Languages, 3, 258-267.

Xun, M. (2006). Exploration of approaches to second vocabulary learning. Foreign Language World, 1, 22-27.

Zahar, R., Cobb, T., \& Spada, N. (2001). Acquiring vocabulary through reading: Effects of frequency and contextual richness. Canadian Modern Language Review, 57, 740-752. http://dx.doi.org/10.3138/cmlr.57.4.541

\section{Copyrights}

Copyright for this article is retained by the author(s), with first publication rights granted to the journal.

This is an open-access article distributed under the terms and conditions of the Creative Commons Attribution license (http://creativecommons.org/licenses/by/3.0/). 